\title{
Giant aneurysm of saphenous vein graft to right coronary artery
}

\author{
Mohammed W. Khalil, Syed S. Qadri, FRCS, and Mubarak Chaudhry, FRCS
}

A 64-year-old white man presented with hemoptysis. He underwent coronary artery bypass grafting (CABG) in 1982, followed by a redo-CABG in 1992, which involved a venous graft to his right coronary artery. A chest radiograph revealed a large shadow on the right border of the heart. This was thought to be a lung tumor, because he is a smoker. Chest computed tomography $(\mathrm{CT})$ revealed that it was a large aneurysm of the saphenous vein graft to the right coronary artery (Figures 1 and 2). The graft was patent, with a large lumen and a large clot in the aneurysmal portion, compressing the right atrium but not causing symptoms, possibly because of its insidious and slow progress.

The hemoptysis was the result of an infective process in the left upper lobe of the lung, which resolved with antibiotics.

True aneurysms of aortocoronary saphenous vein grafts are a relatively rare complication of bypass surgery. ${ }^{1,2}$ Complications of thrombosis, embolization, or rupture are potentially fatal and, therefore, require immediate surgical intervention. ${ }^{2,3}$ However, our patient had multiple comor-

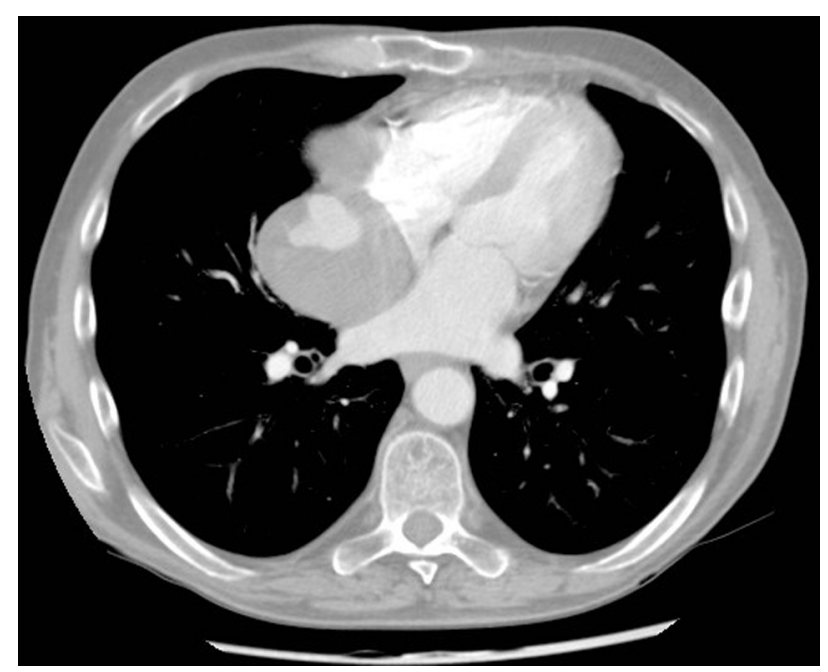

FIGURE 1. Computed tomographic scan showing the giant aneurysm.

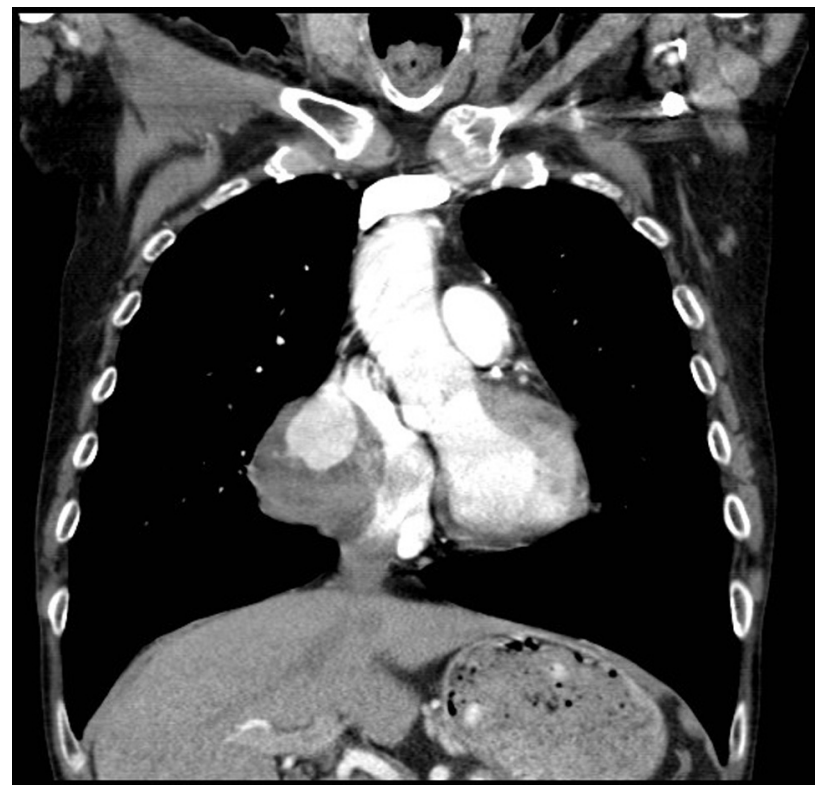

FIGURE 2. Another view of the computed tomographic scan showing the giant aneurysm.

bidities, and surgical intervention was considered to have an unacceptable risk.

Care must therefore be taken while interpreting CT scans in patients presenting with respiratory tract symptoms, because this could be confused with pericardial cysts or lung masses, especially if the graft completely blocked and filled with thrombus. The history of CABG should raise a high index of suspicion.

\section{References}

1. Chiappini B, Poncelet A, Noirhomme P, Verhelst R, Rubay J, Funken JC, et al. Giant aneurysm of aortocoronary saphenous vein graft compressing the left pulmonary artery. J Card Surg. 2006;21:425-7.

2. Mayglothling J, Thomas MP, Nyzio JB, Strong MD, Samuels LE. Aneurysm of aortocoronary saphenous vein graft: case report and literature review. Heart Surg Forum. 2004;7:E317-20.

3. Kalimi R, Palazzo RS, Graver LM. Giant aneurysm of saphenous vein graft to coronary artery compressing the right atrium. Ann Thorac Surg. 1999;68: 1433-7.

\footnotetext{
From the Department of Cardiothoracic Surgery, Castle Hill Hospital, Cottingham, United Kingdom.

Disclosures: Authors have nothing to disclose with regard to commercial support.

Received for publication May 8, 2013; accepted for publication May 13, 2013; available ahead of print Aug 12, 2013.

Address for reprints: Mohammed W. Khalil, Department of Cardiothoracic Surgery, Castle Hill Hospital, Cottingham, United Kingdom (E-mail: wesam @ doctor.com). J Thorac Cardiovasc Surg 2013;146:1544 $0022-5223 / \$ 36.00$

Copyright $\Subset 2013$ Published by Elsevier Inc. on behalf of The American Association for Thoracic Surgery

http://dx.doi.org/10.1016/j.jtcvs.2013.05.037
} 